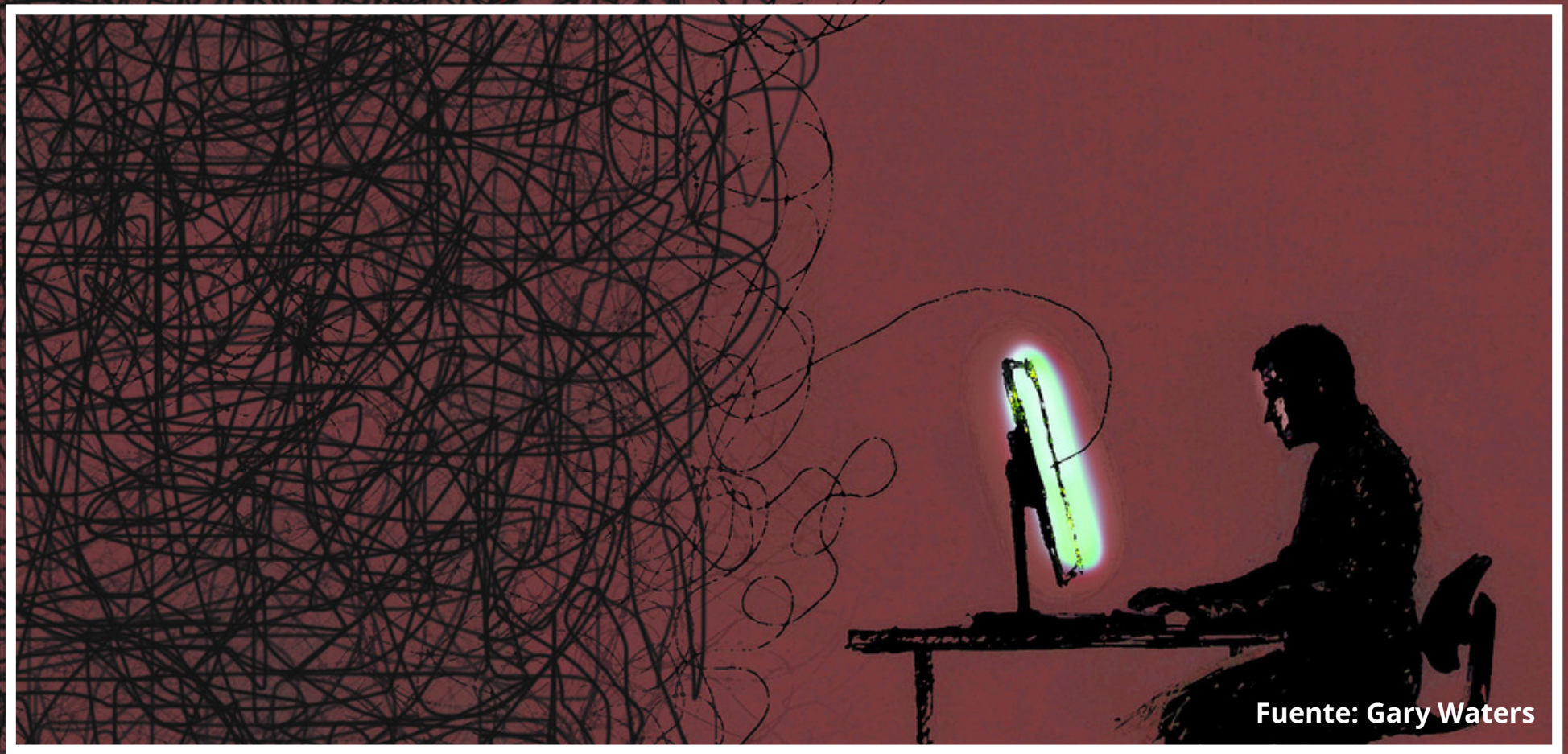

\title{
¿Pueden los remedios difundidos por las redes sociales prevenir y curar la COVID-19?
}

doi: $10.52749 /$ rh.v1i1.7

\section{ENRIQUE NEYRA ID https://orcid.org/0000-0001-7570-7121}

Bachiller en Ciencias Biológicas y Licenciado en Biología Pesquera por la Universidad Nacional de Trujillo. Miembro de la Sociedad Secular Humanista del Perú y conductor del programa de divulgación científica A la ciencia.

$\checkmark$ enriqneyra31@gmail.com

Resumen. La pandemia de COVID-19 no solo nos viralizó con un nuevo agente patógeno sino también con un sinfín de desinformación difundida mayormente por las redes sociales destacándose la promoción de una variedad de remedios caseros y medicamentos a los que se les atribuía propiedades curativas y efectivas contra la COVID-19. En este artículo se abordaron cuatro de los principales productos difundidos: azitromicina, hidroxicloroquina, ivermectina y el remedio casero a base de ajo, kion, cebolla, y miel. Se comprobó que la azitromicina no es un antibiótico natural sino sintético y combate las infecciones bacterianas producidas por la COVID-19. Además, tanto la hidroxicloroquina como la ivermectina carecen de estudios suficientes que prueben su eficacia contra esta enfermedad. Así mismo, si bien es cierto que a cada ingrediente del "brebaje milagroso" se le atribuye beneficios antinflamatorios y antimicrobianos, su mezcla no garantiza un efecto sobre la COVID-19.

Palabras clave: azitromicina, COVID-19, desinformación, hidroxicloroquina, ivermectina, pandemia

\section{Cómo citar este artículo:}

Neyra, E. (2021). ¿Pueden los remedios difundidos por las redes sociales prevenir y curar la COVID-19? Revista Humanista, 1(1), 39-42. https://doi.org/10.52749/rh.vlil.7

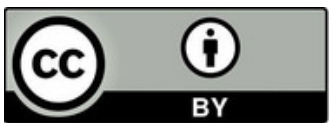




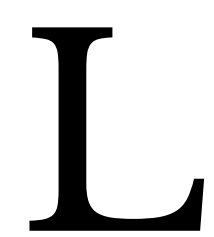

a actual pandemia ha desatado la difusión viralizada a través de las redes sociales de un sinfín de recetas, productos caseros $y$ medicinas para prevenir y curar la COVID-19. Cabe resaltar que estos productos no han sido autorizados por la OMS y solo promueven la desinformación, algo que resulta más peligroso que la pandemia misma.

Muchos de estos productos se venden con la premisa de contener "antibióticos naturales" como la azitromicina. Otros de los fármacos más mediáticos durante esta crisis sanitaria mundial, como la hidroxicloroquina y la polémica ivermectina, son el foco de atención de medios nacionales e internacionales desde hace unas semanas.

Por otro lado, la difusión de los famosos remedios caseros también se ha viralizado por las principales redes sociales. Uno de ellos, el jarabe a base de ajo, kion, cebolla y miel, y en algunos casos, canela - tal vez para darle un mejor sabor al menjunje-, se difunde y promociona ampliamente como la cura milagrosa para esta enfermedad.

A pesar que algunos de estos productos poseen propiedades antioxidantes y componentes antimicrobianos, es falso que uno de sus componentes sea la azitromicina, pues es un antibiótico fabricado en laboratorio y no proviene de plantas naturales. A esto le sumamos que la proclamada mezcla curativa carece de evidencia científica que sustente sus propiedades curativas y de prevención para la COVID-19. Es más, promover en redes su preparación y consumo como único tratamiento incita a la automedicación, lo que se está convirtiendo en un problema cada vez más peligroso.

Si bien es cierto, la azitromicina, la hidroxicloroquina, la ivermectina y otros compuestos son considerados por muchos países para tratar la enfermedad ocasionada por el nuevo coronavirus, la OMS ha descartado tajantemente que hasta ahora haya algún medicamento o tratamiento autorizado para combatirla. Por si fuera poco, la azitromicina sí se utiliza para infecciones bacterianas, pero los ensayos clínicos con hidroxicloroquina fueron suspendidos por la OMS debido a la falta de pruebas, mientras que el uso de la ivermectina ha sido totalmente descartado.

Es por esto que en el presente ensayo se analiza si existen pruebas oficiales que respalden lo difundido por redes acerca de estos medicamentos y remedios caseros, con el fin de transmitir resultados fiables al público en general.

En principio, algo importante a destacar es la definición y utilidad en la medicina de los antibióticos, también llamados antibacterianos. Se trata de medicamentos destinados a combatir infecciones ocasionadas solo por bacterias, por eso sus efectos son nulos en virus, pero de estos se encargan los antivirales (Healthy Children, 2016).

Teniendo en cuenta su función, el uso de los antibióticos en la lucha contra la COVID-19 no combate específicamente el virus, sino las infecciones secundarias que puedan sufrir los pacientes, siempre y cuando su administración sea bajo la indicación de un médico (OMS, 2020).

Ahora bien, poniendo en contexto a la famosa azitromicina, es válido afirmar que es un antibiótico utilizado en tratamientos contra infecciones bacterianas (Clínica Universidad de Navarra, 2020), especialmente las que afectan el aparato respiratorio (AEMPS, 2018), pero en las redes sociales son virales las publicaciones que afirman que se encuentra en plantas como el eucalipto, la menta, el limón, la cebolla, el ajo, el kión, el matico y hasta en el clavo de olor; sin embargo, no es un antibiótico natural, sino sintético, pues se elabora en laboratorios autorizados a partir de elementos químicos ya existentes en otro antibiótico, la eritromicina, que a su vez es producida por una bacteria, Saccharopolyspora erythraea, anteriormente conocida como Streptomyces erytrheus. Así pues queda demostrado el origen sintético de la azitromicina y se refuta totalmente su origen natural con el fin de desvirtuar la información errónea difundida en redes (AFP Factual, 2020).

Otros medicamentos también han sido ampliamente comentados en los medios no sin polémica, por ejemplo, la hidroxicloroquina (un análogo de la cloroquina), que fue promovida por Donald Trump y compañía como portadora de propiedades efectivas contra la COVID-19.

En los primeros ensayos, se comprobó que este medicamento tenía un fuerte efecto in vitro anti SARS-CoV-2 (IntraMed, 2020). Diversos estudios, como el de Gautret et al. (2020), demostraron - pese al reducido tamaño de su muestra- que reducía significativamente la 
carga viral en pacientes con COVID-19 cuando se reforzaba con azitromicina. En consecuencia, la OMS autorizó ensayos clínicos dentro del proyecto Solidarity para comprobar su eficacia, no obstante, recientemente, unos estudios pusieron en duda la inocuidad del fármaco, por lo que la OMS decidió suspender los ensayos hasta tener pruebas eficientes de su inocuidad (OMS, 2020). Además, se ha comprobado que la tasa de mortalidad no se redujo en pacientes que recibieron el medicamento (ABC, 2020).

En cuanto a la polémica ivermectina -fármaco generalmente utilizado como antiparasitario-, actualmente se considera como uno de los tratamientos contra la COVID en el Perú, incluso durante estas últimas semanas se ha difundido su uso sin prescripción médica para prevenir y curar. Pero lo más peligroso es que la publicidad a través de las redes no la han hecho anónimos, sino médicos y personal de salud. Los efectos de dicha difusión dieron pie a lamentables y hasta vergonzosas noticias, como lo ocurrido en Loreto, en donde un grupo evangélico vacunó sin autorización médica a cerca de cinco mil personas con el medicamento bajo la excusa de que el coronavirus era consecuencia del fin de los tiempos y obra del diablo, mientras que la vacuna de ivermectina era la "salvación" (Diario AS peru, 2020). Esta situación, promovida también por el propio alcalde de la ciudad, ocasionó que un gran porcentaje de las cinco mil personas acudiera a emergencias por efectos secundarios adversos como mareos, taquicardias y hasta necrosis en la zona de la inyección (Ojo Público, 2020).

A pesar de esto, el Ministerio de Salud aún incluye en su protocolo tanto a la ivermectina como a la hidroxicloroquina, y deja a criterio de cada médico su uso. En respuesta, la comunidad médica del Perú ha exhortado al Ministerio para que reconsidere el uso de estos fármacos, pues hasta ahora no hay estudios confiables - no solo in vitro- que aseguren su éxito. Por su parte, la OMS todavía considera que un medicamento es confiable para combatir la COVID-19.

En cuanto a los productos naturales, como el mencionado "brebaje milagroso" a base de kion, ajos, cebolla, miel y canela, cabe recordar que desde siempre, los productos naturales han sido preferidos por un gran porcentaje de la población, pues se tiende a relacionar lo natural con lo beneficioso (falacia naturalista) y se argumenta que antiguamente toda enfermedad era combatida por plantas medicinales $u$ otros productos naturales. Esta falacia ha sido reforzada durante la pandemia tanto en redes sociales como en medios de comunicación con la promoción de brebajes presuntamente milagrosos. En casos extremos se ha llegado a afirmar que serían la única medida de prevención y curación de la enfermedad, si se los toma antes del contagio porque reforzarían el sistema inmunológico.

Actualmente solo hay evidencia de que, individualmente, cada uno de los componentes del "brebaje" tiene ciertos beneficios antioxidantes, antiinflamatorios y hasta antimicrobianos - como el ajo-, pero lo cierto es que no hay sustento científico para afirmar que toda la mezcla tenga las atribuidas propiedades curativas contra el SARS-CoV-2 ni que combata las enfermedades respiratorias en general, pues para ello se necesita más estudios. A lo mucho, en conjunto puede tener propiedades antioxidantes o hasta antimicrobianas, pero serían solo supuestos a base de generalizar las propiedades individuales de cada insumo natural (AFP Actual, 2020).

En esta misma línea, las recomendaciones de aumentar por encima de nuestras necesidades nutricionales el consumo de vitamina $\mathrm{C}$ y $\mathrm{D}$, así como otros minerales son totalmente rechazadas por profesionales de la salud, quienes instan a tomar suplementos vitamínicos siempre y cuando haya prescripción médica, de lo contrario podría producirse efectos adversos a lo esperado inicialmente (La Voz de Guanacaste, 2020).

Finalmente, algo muy importante a tener en cuenta en medicina es la dosificación. Cada prescripción médica se elabora en función de los datos de cada paciente, como el peso. La difusión de remedios caseros y antibióticos no consideración los aspectos biológicos de cada persona, por lo que quienes los ingieren corren el riesgo de sufrir efectos secundarios mediatos o inmediatos por sobredosificación. También cabe recordar que la OMS y la OPS (Organización Panamericana de Salud) reafirman que no hay producto natural o fármaco que prevengan la enfermedad ocasionada por el nuevo coronavirus, aunque sí hay alimentos saludables que refuerzan el sistema inmunológico. 


\section{Conclusiones}

La azitromicina es un antibiótico que no se encuentra en productos naturales, sino que es elaborado en laboratorios y se usa específicamente en infecciones respiratorias bacterianas que surgen a raíz del COVID-19.

Por otro lado, tanto la hidroxicloroquina como la ivermectina, si bien es cierto que en el Perú se consideran como opciones para tratar la enfermedad ocasionada por el SARS-CoV-2, carecen de estudios y evidencias con sustento confiable, por lo que su uso arriesga la salud de la población, como lo ocurrido en Loreto.

De la misma forma, los remedios caseros "milagrosos" no tienen sustento científico que sostenga la veracidad de sus supuestas propiedades preventivas y curativas.

La Organización Mundial de la Salud recomienda como únicas medidas preventivas $-\mathrm{y}$ con evidencia científica- el lavado de manos, el uso de mascarillas y el distanciamiento social. Por lo tanto, la difusión de otros métodos para combatir la COVID-19 generan desinformación e inducen a la peligrosa práctica de la automedicación, algo que tanto la Organización Mundial de la Salud como otras instancias exhortan no hacer, pues las consecuencias podrían ser peligrosas. Así, en esta coyuntura, es mejor no solo informarse antes y consultar siempre a un médico sino ejercer pensamiento crítico, ya que la capacidad de analizar la información y contrastarla con evidencias ayuda a evitar consecuencias nefastas, como lo que ocurrió en Loreto y en diversas partes del país y el extranjero.

Si bien es cierto que la comunicación informada de las autoridades con la población no ha sido efectiva y debe mejorar con rapidez y eficacia, también lo es que ha habido un total desdén hacia la ciencia en todos los gobiernos del mundo, y que las consecuencias de todo ello las estamos viviendo hoy en día. El cambio es urgente.

\section{Referencias}

AEMPS. (2018). Ficha técnica azitromicina cinfa 500 mg comprimidos recubiertos con película efg. (Ficha tec. 65600). https://cima.aemps.es/cima/dochtml/ft/65600/FichaTecnica

Chávez, C. (20 de junio de 2020). Grupo de médicos recomiendan descontinuar uso no supervisado de hidroxicloroquina e ivermectina. OJO PÚBLICO. $\underline{\text { https://ojo- }}$ publico.com/1909/medicos-piden-cautela-en-uso-dehidroxicloroquina-e-ivermectina

Clínica Universidad de Navarra. (2020). Antibióticos vía sistémica, macrólidos. Azitromicina. https://www.cun.es/enfermedadestratamientos/medicamentos/azitromicina

HealthyChildren.org. (13 de abril de 2016). Consejos para tratar los virus, los hongos $y$ los parásitos. https://www.healthychildren.org/Spanish/health-

issues/conditions/treatments/Paginas/Tips-For-Treating-VirusesFungi-and-Parasites.aspx

Gautret, P., Lagier, J.C., Parola, P., Hoang, V.T., Meddeb, L., Mailhe, M., Doudier, B., Courjon, J., Giordanengo, V., Esteves Vieira, V., Tissot Dupont, H., Honoré, S., Colson, P., Chabriére, E., La Scola, B., Rolain, J.M., Brouqui, P., Raoult, D. (2020). Hydroxychloroquine and azithromycin as a treatment of COVID19:results of anopen-label non-randomized clinical trial. International. Journal of Antimicrobial Agents, 56(1), https://doi.org/10.1016/j.ijantimicag.2020.105949

Intramed. (23 de marzo de 2020). Hidroxicloroquina y azitromicina como tratamiento de COVID-19. https://www.intramed.net/contenidover.asp? contenidoid=95791
AFP Factual. (28 de mayo de 2020). La azitromicina es un antibiótico sintético, no se encuentra en la naturaleza. https://factual.afp.com/la-azitromicina-es-un-antibiotico-sinteticono-se-encuentra-en-la-naturaleza

ABC. (19 de junio de 2020). La OMS suspende de nuevo los ensayos con hidroxicloroquina para la covid-19. https://www.abc.es/salud/enfermedades/abci-suspende-nuevoensayos-hidroxicloroquina-para-covid-19202006191207 noticia.html

AFP Factual (8 de mayo de 2020). No hay evidencia de que los remedios basados en ajo sean efectivos para prevenir o curar estas dolencias. https://vozdeguanacaste.com/tener-lasdefensas-altas-puede-evitar-el-contagio-de-covid-19/

Organización Mundial de la Salud. (2020). Preguntas y respuestas sobre la enfermedad por coronavirus (COVID-19). https://www.who.int/es/emergencies/diseases/novel-coronavirus2019/advice-for-public/q-a-coronaviruses

Diario AS Perú. (20 de junio de 2020). Qué es la ivermectina, el medicamento de uso veterinario inyectado a miles de personas en Loreto. https://peru.as.com/peru/2020/06/20/actualidad/159266407790 9506.html

Rodríguez, A. (04 de junio de 2020). ¿Tener las defensas altas puede evitar el contagio de COVID-19? LA VOZ de GUANACASTE. $\quad$ https://vozdeguanacaste.com/tener-lasdefensas-altas-puede-evitar-el-contagio-de-covid-19/ 